\title{
The effect of surface termination on glucose oxidation using Ni-modified diamond electrodes
}

\author{
Johanna Svanberg-Larsson ${ }^{1}$, Geoffrey W. Nelson ${ }^{1}$, Luyun Jiang ${ }^{1}$, Robert J. Walker ${ }^{2}$, John S. Foord ${ }^{*}$,1 \\ ${ }^{1}$ Department of Chemistry, University of Oxford, Oxford, OX1 3TA, UK \\ ${ }^{2}$ Department of Materials, Imperial College London, Exhibition Road, London, SW7 2BP UK
}

Received XXXX, revised XXXX, accepted XXXX

Published online XXXX

Key words: Boron-doped diamond, nickel, glucose, electrochemistry.

${ }^{*}$ Corresponding author: e-mail john.foord@chem.ox.ac.uk, Phone: +44-xx-xxxxxxx, Fax: +xx-xx-xxx

This study describes the decoration of hydrogenand oxygen-terminated boron-doped diamond electrodes (BDD) with three different loadings of $\mathrm{Ni}$. The $\mathrm{Ni}$ was deposited electrochemically for 600, 400 and $100 \mathrm{~s}$ on both hydrogen-terminated BDD (BDDH) and oxygenterminated BDD (BDDO). SEM showed that all Ni particles were roughly spherical in shape, but distribution and size varied with electrode termination: a uniform coverage with a particle size dependent on deposition duration was achieved on BDDH, but on BDDO the particles deposited primarily along surface ridges and had similar sizes for all three deposition times.
The performance of the samples was then tested using glucose sensing as an exemplar application. It was found that glucose oxidation varies greatly between electrodes at concentrations similar to those found in human blood. The variability between the samples was attributed to surface differences between electrodes and the difference in particle location. Amperometry using BDDs decorated with the $100 \mathrm{~s} \mathrm{Ni}$ deposition gave a stable current response with respect to glucose concentration in the range $0.1-13 \mathrm{mM}$ with much higher glucose oxidation currents being observed for the Ni nanoparticles deposited on the hydrogenated diamond surface.
1 Introduction Boron-doped diamond electrodes (BDD) have become practical electrodes for use in electrochemistry given the advances in chemical vapour deposition techniques that make BDD wafers with a boron concentration exceeding $10^{20} \mathrm{~cm}^{-2}$ readily available.[18] These BDD electrodes have numerous advantages over other common working electrodes: a wide potential window, low background current and excellent chemical stability.[1,9-12] Oxygen-terminated BDDs (BDDO) have additionally shown a resistance to oxygen interference, $[13$, 14] but more interestingly the BDD can be explicitly terminated to be either hydrophilic or hydrophobic.[10,15] The hydrophobic surface is achieved by hydrogen termination, which alters the electrochemical performance of the BDD, [11,16-19] whereas BDDO is hydrophilic.

The performance of BDDs as working electrodes can be further enhanced through modification of the surface with metal or metal oxide particles.[8,20-24] Nickel, for example, is of increasing interest due to its potential utility in a range of applications including water splitting,[25, 26 ] the oxidation of methanol and other primary alcohols for use in green energy fuel cells,[27-30], and the oxidation of adenine, DNA, steroid hormones and glucose for sensing purposes.[31-33,25] Enzymatic glucose sensing is currently the most common method of glucose sensing, but suffers from the instability inherent to enzymes.[34] Another possibility is the enzyme-free oxidation of glucose, which has been the topic of much research.[6,24,27,25, 32,34-36] For example, glucose can be electrooxidised to glucolactone[37-39] by the $\mathrm{Ni}(\mathrm{OH})_{2} / \mathrm{NiOOH}$ catalytic redox couple[25,35,34], which can be obtained from oxidation of Ni metal in alkali solution.[33,35,40,41]

Given the importance of glucose sensing in fields ranging from medical applications to the food industry[42] 
and fuel cells, $[6,43-45]$ there is a lot of work in the literature which documents the use of Ni particles for glucose oxidation, both on BDD and other substrates. However, most of the work currently reported in the literature that studies the use of Ni particles on BDD electrodes for glucose oxidation exclusively uses BDDO.[25,34,39,26] Given that BDDH has been shown to have increased conductivity and better electrical contact with deposited metal particles, one of the main aims of the work presented here was to compare the oxidation of glucose on $\mathrm{Ni} / \mathrm{BDDH}$ to the identically decorated BDDO. Furthermore, Hutton et. al studied the effect of Ni loading on the oxidation of glucose, focussing only on the oxygen-terminated BDD electrode;[26] hence a secondary aim of this project was to fill this gap by studying three different amounts of deposited $\mathrm{Ni}$ and comparing the glucose oxidation results between the oxygenated and hydrogenated samples to determine not only the optimal surface termination of the BDD, but also the optimal Ni loading.

2 Experimental methods All six nominally identical polycrystalline BDDs ([B]>10 $0^{20} \mathrm{~cm}^{-2}$ ) used in this work were electrochemical grade and purchased from Element Six Co (UK). Throughout this work, water refers to Millipore water with a resistivity of $18.2 \mathrm{M} \Omega \mathrm{cm} .70 \%$ $\mathrm{HNO}_{3}$ was purchased from Fischer Scientific and all other chemicals were of analytical grade, obtained from Sigma Aldrich and used without further purifcation. Deaeration was done by bubbling $\mathrm{N}_{2}$ though the solution for at least 20 min. All electrochemistry was performed using a standard three-electrode cell comprising a Pt counter electrode, a $1 \mathrm{M} \mathrm{Ag} / \mathrm{AgCl}$ reference electrode and the Ni decorated BDD as the working electrode with an area of $0.46 \mathrm{~cm}^{2}$ connected to an Autolab potentiostat (Utrecht, Netherlands) operated using the GPES software.

2.1 Preparing the BDDs Three clean BDDs were oxygen terminated by refluxing in $70 \% \mathrm{HNO}_{3}$ for at least four hours. Hydrogen termination of another three BDDs was achieved by subjection to hydrogen plasma at $600^{\circ} \mathrm{C}$, 45 torr and $1.5 \mathrm{~kW}$ power for 45 minutes.

Cleaning At the end of each experiment, the $\mathrm{Ni}$ was removed by submerging the $\mathrm{BDD}$ in a $3 \% \mathrm{FeCl}_{3}$ solution for ten minutes twice. Leaving the $\mathrm{BDD}$ in $3 \% \mathrm{FeCl}_{3}$ for longer periods or at higher concentrations of $\mathrm{FeCl}_{3}$ resulted in trace amounts of Fe being deposited on the BDD. Nickel hydroxides were removed from the surface by first removing the hydroxide layers in $6 \mathrm{M} \mathrm{HCl}$ for at least $30 \mathrm{~min}$ utes, and then the $\mathrm{Ni}$ was removed using the $3 \% \mathrm{FeCl}_{3}$ as described. Cleanliness was confirmed by the absence of $\mathrm{Ni}$ redox peaks in the cyclic voltammogram taken in $0.1 \mathrm{M}$ $\mathrm{HNO}_{3}$ between 2.5 and $-1.7 \mathrm{~V}$ at a scan rate of $0.1 \mathrm{Vs}^{-1}$, starting at $0 \mathrm{~V}$. If necessary, the BDDs were submerged in aqua regia over night.

2.2 $\mathrm{Ni}$ deposition and enrichment $\mathrm{Ni}$ deposition was accomplished using amperometric deposition at $-1.3 \mathrm{~V}$ for either 100,400 or $600 \mathrm{~s}$ in a $1 \mathrm{mM} \mathrm{Ni}\left(\mathrm{NO}_{3}\right)_{2}$ in $0.1 \mathrm{M}$ acetate buffer $(\mathrm{pH}=5)$. This procedure is known to deposit a mix of $\mathrm{Ni}$ metal and $\mathrm{Ni}(\mathrm{OH})_{2}$ as per the following reactions:[25]

$$
\begin{gathered}
\mathrm{Ni}^{2+}+2 e^{-} \rightarrow \mathrm{Ni}^{0} \\
\mathrm{NO}_{3}^{-}+7 \mathrm{H}_{2} \mathrm{O}+8 e^{-} \rightarrow \mathrm{NH}_{4}^{+}+10 \mathrm{OH}^{-} \\
\mathrm{Ni}^{2+}+2 \mathrm{OH}^{-} \rightarrow \mathrm{Ni}(\mathrm{OH})_{2}
\end{gathered}
$$

The deposited Ni was then enriched with hydroxide by cycling between 0.15 and $0.55 \mathrm{~V}$ in a $1 \mathrm{M} \mathrm{KOH}$ solution as previously described by Toghill and Shpilevaya.[25,35] This enrichment process thickens the $\mathrm{Ni}(\mathrm{OH})_{2}$ layer by oxidising the $\mathrm{Ni}$ metal.[25] $\mathrm{Ni}(\mathrm{OH})_{2}$ will then undergo catalytic conversion to, and from, $\mathrm{NiOOH}$ during the oxidation of glucose.[25,33,34]

2.3 SEM Scanning electron microscopy (SEM) was used to ascertain the morphology and distribution of the asdeposited Ni particles on the conducting BDD substrates. The BDDH samples were imaged using a Hitachi S-4300 field emission scanning electron microscope as was the $100 \mathrm{~s} \mathrm{Ni}$ deposition onto BDDO. Due to equipment unavailability, the 600 and $400 \mathrm{~s} \mathrm{Ni/BDDO}$ were imaged using a different SEM. These two samples were imaged using a JEOL JSM-5610LV. An accelerating voltage of $20 \mathrm{kV}$ was used for all samples.

2.4 Glucose measurements The sensitivity and behaviour of the Ni decorated BDDs were probed using glucose sensing. Ni/BDD systems have been previously used as glucose sensors, making glucose sensing an ideal test case for observing alterations in performance with both the $\mathrm{Ni}$ loading and the BDD termination.

Cyclic voltammetry Cyclic voltammetry (CV) was used to observe the general redox behaviour of glucose solutions with the Ni/BDD systems. Glucose concentrations ranging from 1 to $10 \mathrm{mM}$ (similar to the glucose levels in human blood) in a $1 \mathrm{M} \mathrm{KOH}$ supporting electrolyte were tested with cyclic voltammetry between the potentials of 0.2 to $0.5 \mathrm{~V}$ at a scan rate of $0.05 \mathrm{Vs}^{-1}$. The solution was stirred at $700 \mathrm{rpm}$. This experiment also gave the oxidation potential of $0.47 \mathrm{~V}$ specific to the $\mathrm{Ni} / \mathrm{BDD}$ system that was later used in the amperometric experiments.

Amperometry Amperometric measurements were used to determine whether the current would increase linearly with glucose concentrations when the glucose concentration was decreased. Briefly, the Ni/BDD electrode was put in a $1 \mathrm{M} \mathrm{KOH}$ solution for $50 \mathrm{~s}$ after which aliquots of concentrated glucose were injected at intervals of $50 \mathrm{~s}$, in a stirred solution. The potential was held at the glucose oxidation potential at $0.47 \mathrm{~V}$, as found by cyclic voltammetry, for the duration of the experiment.

\section{Results and discussion}

3.1 Deposition of $\mathrm{Ni} \mathrm{Ni}$ was deposited onto both the oxygenated and hydrogenated BDD (BDDO and BDDH) from a deaerated $1 \mathrm{mM} \mathrm{Ni}\left(\mathrm{NO}_{3}\right)_{2}$ solution for 600,400 
and $100 \mathrm{~s}$ respectively. The charge equivalents of $\mathrm{Ni}$ deposited on each electrode, as found by integrating the deposition curve, is given in Table 1. The distribution and

Table $1 \mathrm{Ni}$ deposition (in $\mathrm{mC}$ ) on BDDH and BDDO

\begin{tabular}{llll}
\hline & $600 \mathrm{~s}$ & $400 \mathrm{~s}$ & $100 \mathrm{~s}$ \\
\hline BDDH & 430 & 240 & 70 \\
BDDO & 310 & 220 & 65 \\
\hline
\end{tabular}

morphology of the as-deposited Ni was then inspected using SEM, shown in Fig. 1.

The most striking difference between the Ni on BDDO and on BDDH is the difference in particle distribution on the electrode surface; on BDDH the Ni particles have a uniform distribution showing no preference for flat or pitted areas. Conversely, on BDDO the Ni preferentially sits in pitted areas or along ridges (Fig. 1D-F). As shown in Fig. 1, BDDH (Fig. 1A-C) has a Ni nanoparticle coverage which increases with the deposition time - these particles diminish in both size and number for the $100 \mathrm{~s}$ deposition. The particle size of the $600 \mathrm{~s} \mathrm{Ni}$ is approximately twice as large on BDDO compared to BDDH; the difference in amount deposited resulting in the different coverages as previously described. For the $100 \mathrm{~s}$ deposition, however, the particles are more than one order of magnitude larger on BDDO than BDDH. All samples have a Ni morphology that is approximately spherical. The uniform coverage of $\mathrm{Ni}$ on the hydrogenated surface in comparison to the oxidised surface is liley to correlate to the addtional conductivity from the so-called surface conductivity of the hydrogenated surface.

3.2 CV response to glucose oxidation Following deposition, the $\mathrm{Ni}$ was enriched to $\mathrm{Ni}$ hydroxide in $1 \mathrm{M}$ $\mathrm{KOH}$ for 500 cycles between 0.15 and $0.55 \mathrm{~V}$ so as to improve the electrochemical activity of the sample. The enriched $\mathrm{Ni}$ on BDD was then used to probe the redox behaviour of differing glucose solutions $(1-10 \mathrm{mM})$ in 1 $\mathrm{M} \mathrm{KOH}$. The voltammograms, together with the current density versus glucose concentrations plots, are shown in Fig. 2 for BDDH and Fig. 3 for BDDO. In the forward scan, the oxidation peak is that to $\mathrm{NiOOH}$ which is then reduced by the irreversible oxidation of glucose such that on the back scan $\mathrm{Ni}(\mathrm{OH})_{2}$ is again oxidised to $\mathrm{NiOOH}$. The small reduction peak is the reduction of residual $\mathrm{NiOOH}$ to $\mathrm{Ni}(\mathrm{OH})_{2} \cdot[25]$

The two fits for the current response to glucose concentration shown in Fig. 2 and 3 are for all ten glucose concentrations (red dashed line) and for the concentration range 4-10 mM (blue solid line). The response of Ni/BDDH to glucose is most linearly dependent on the glucose concentration for the $400 \mathrm{~s} \mathrm{Ni}$ deposition (Fig. 2B and F) and the data is most scattered (lowest $\mathrm{R}^{2}$ value) for the $600 \mathrm{~s} \mathrm{Ni}$ deposition (Fig. 2A and D). There seems to be rather little correlation between the current response observed to glucose and the Ni coverage however. The data is also very scattered particularly at low glucose concentration; the dif- ference in $\mathrm{R}^{2}$ value shows that the current response is more linear with respect to glucose concentration if the lowest concentrations are not included in the analysis. Two conclusions seem to be indicated. Firstly the oxidation of glucose at these Ni modified diamond electrodes is likely to be controlled by diffusion of glucose to the densely covered Ni nanoparticle array rather than being limited by a surface reaction at the surface of the Ni nanoparticles.[26] Hence changes in Ni nanoparticle coverage have virtually no effect on the magnitude of the oxidation current observed. Secondly, some other factor which is especially prominent at low glucose concentration seems to have a salient effect in controlling the current response observed as witnessed by the scatter in the current response observed. Given the sensitivity of the electrode to the conditioning to produce the Ni hydroxide layer, this is most probably associated with the level of oxidation of the surface of the Ni nanoparticles which is difficult to maintain at a constant level as the electrode is used.

Rather similar behaviour is observed superficially on the $\mathrm{Ni}$ on BDDO electrodes. Again scatter in the data is observed at low glucose concentrations and the current response seems to show no particular correlation to the Ni particle concentration indicative of diffusion controlled rather than surface limited behaviour. However it is noteworthy that the current density observed in the $\mathrm{CV}$ data is approximately an order of magnitude smaller on the oxidised electrode compared to the hydrogenated electrode. The most obvious explanation for this - a current seemingly independent of nanoparticle density but much lower than the diffusion limit seen on the hydrogenated surface is that macroscopic regions (of dimension of the order or greater than the glucose diffusion layer thickness of the order of $100 \mu \mathrm{m}$ in these experiments) are electrochemically inactive so significantly reducing the current response. This partially correlates with the very heterogeneous deposition of $\mathrm{Ni}$ seen in the SEM analysis which also suggests significant areas of the electrode are likely to remain unmodified by the presence of $\mathrm{Ni}$.

3.3 Amperometric glucose response Amperometry was then used to gauge the sensitivity of the best of the $\mathrm{Ni} / \mathrm{BDD}$ samples, and the responses are shown in Fig. 4. As was also found by cyclic voltammetry, the signal from $\mathrm{BDDH}$ is significantly higher than for BDDO. However, this does not correspond to an increase in sensitivity in the oxidation of glucose in the concentration range of interest here; as can be seen in sample data high concentrations (1$13 \mathrm{mM}$ ) of glucose, or lower concentrations (0.1-1.3 mM) BDDO can easily be detected at these Ni treated BDDH and BDDO electrodes. However, whilst some modified electrodes worked well considerable variability in performance was sometimes seen as in Fig. 4A. The variability of the glucose peaks observed by $\mathrm{CV}$ is reduced in these potentiostatic measurements, except perhaps for BDDO in the 1-10 $\mathrm{mM}$ glucose range, which may suggest that some part of the variability may have arisen from the Ni reduc- 


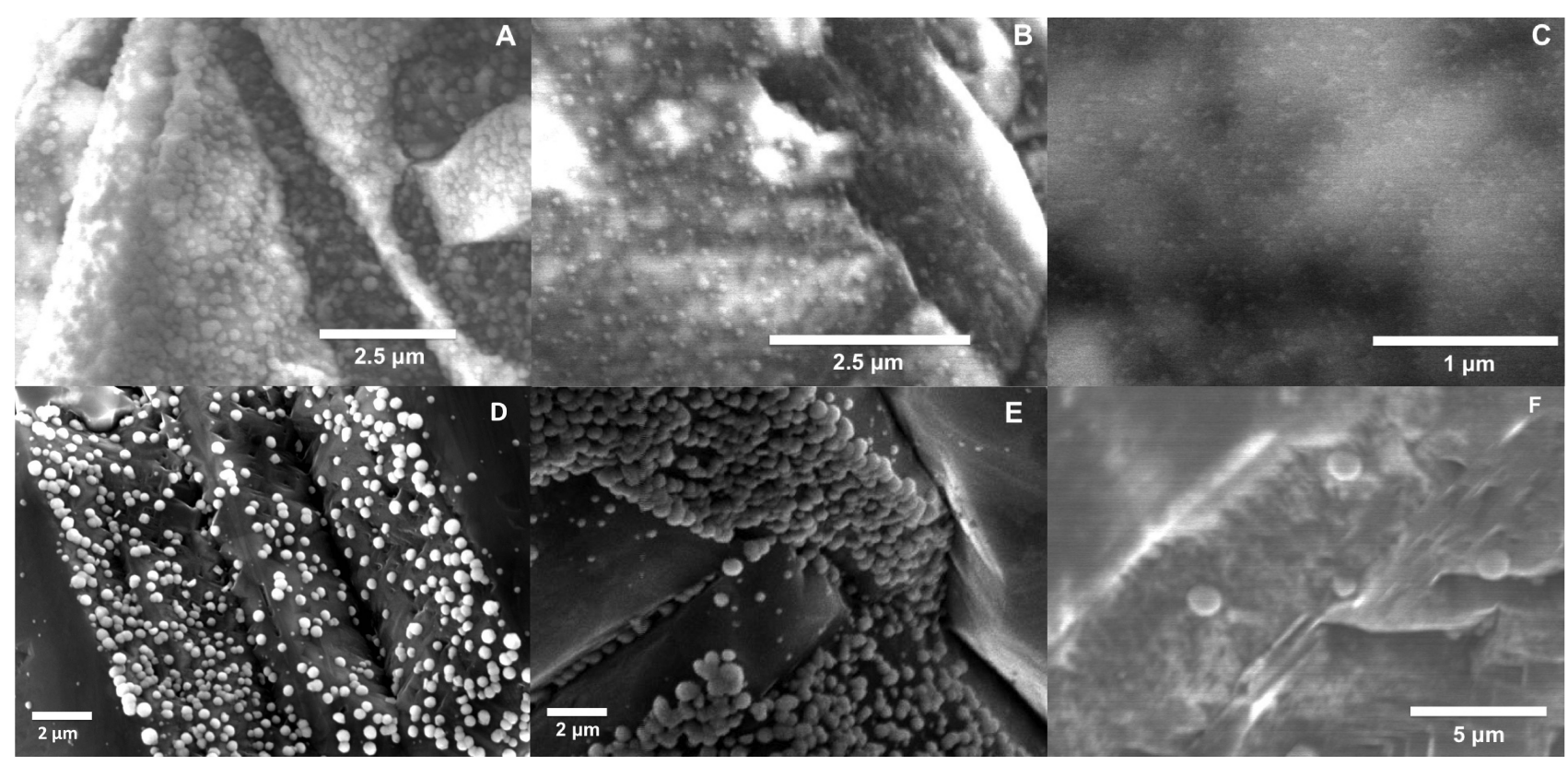

Figure $1 \mathrm{SEM}$ images of $1 \mathrm{mM} \mathrm{Ni}\left(\mathrm{NO}_{3}\right)_{2}$ in $0.1 \mathrm{M}$ acetate buffer deposited at $-1.3 \mathrm{~V}$ for 600 (A), 400 (B) and $100 \mathrm{~s}$ (C) on BDDH and on BDDO for 600 (D), 400 (E) and $100 \mathrm{~s}$ (F). All images were recorded using a $20 \mathrm{kV}$ accelerating voltage.

tion peak which was traversed in $\mathrm{CV}$ but not in the potentiostatic method discussed in this section.

4 Conclusion This work investigated the effect of BDD termination on the oxidation of glucose aided by hydroxide-enriched $\mathrm{Ni}$ particles. The Ni particles were deposited on the clean, explicitly terminated BDD by a potentiostatic method for 600,400 and $100 \mathrm{~s}$ to achieve different Ni loadings. The as-deposited $\mathrm{Ni}$ was then enriched to $\mathrm{Ni}(\mathrm{OH})_{2}$ prior to being used for glucose sensing. BDDH was found to have slightly higher Ni loadings than BDDO and a more uniform $\mathrm{Ni}$ particle coverage, showing that $\mathrm{Ni}$ deposits and nucleates differently on BDDO compared to BDDH. This might arise from the surface conductivity of the hydrogenated surface which tends to equalise out the conductivity variations seen in the oxidised surface due to the uneven distribution of the boron dopant. Furthermore, cyclic voltammetric oxidation of glucose showed that there was quite considerable variation in electrode sensitivity, which was attributed to variations in the activity of the Ni nanoparticles which depends critically on their level of oxidation. On the whole, less variations were seen for Ni nanoparticles on the oxidised surface compared to the hydrogenated surface. Significantly larger glucose oxidation currents were observed on the hydrogenated surface compared to the oxidised surface. This was attributed in part to large parts of the Ni modified diamond electrode being inactive due to the absence of deposited $\mathrm{Ni}$ in those areas. For the best Ni modified electrodes, reliable glucose detection was demonstrated in the range $0.1-13 \mathrm{mM}$.
Acknowledgements JSL thanks Balliol College for the financial support of the Lady Dervorguilla Scholarship. GWN recognises the support of a research grant from Corpus Christi College.

\section{References}

[1] R. Compton, J. Foord, and F. Marken, Electroanalysis 15(17), 1349-1363 (2003).

[2] T. N. Rao and A. Fujishima, Diamond and Related Materials 9(3), 384-389 (2000).

[3] I. Shpilevaya, W. Smirnov, S. Hirsz, N. Yang, C. E. Nebel, and J. S. Foord, RSC Advances 4(2), 531 (2014).

[4] L. Chen, J. Hu, and J. S. Foord, Physica Status Solidi (a) 209(9), 1792-1796 (2012).

[5] R. L. McCreery, Chemical Reviews 108(7), 2646-2687 (2008).

[6] K. E. Toghill and R. G. Compton, International Journal of Electrochemical Science 5(9), 1246-1301 (2010).

[7] X. Lu, J. Hu, J. S. Foord, and Q. Wang, Journal of Electroanalytical Chemistry 654(1-2), 38-43 (2011).

[8] A. Kraft, International Journal of Electrochemical Science 2, 355-385 (2007).

[9] M. Hupert, A. Muck, J. Wang, J. Stotter, Z. Cvackova, S. Haymond, Y. Show, and G. M. Swain, Diamond and Related Materials 12, 1940-1949 (2003).

[10] G. R. Salazar-Banda, L. S. Andrade, P. A. P. Nascente, P. S. Pizani, R. C. Rocha-Filho, and L. a. Avaca, Electrochimica Acta 51(22), 4612-4619 (2006).

[11] K. Hayashi, S. Yamanaka, H. Watanabe, T. Sekiguchi, H. Okushi, and K. Kajimura, Journal of Applied Physics 81(1997), 744-753 (1997).

[12] M. Panizza and G. Cerisola, Electrochimica Acta 51(2), 191-199 (2005). 

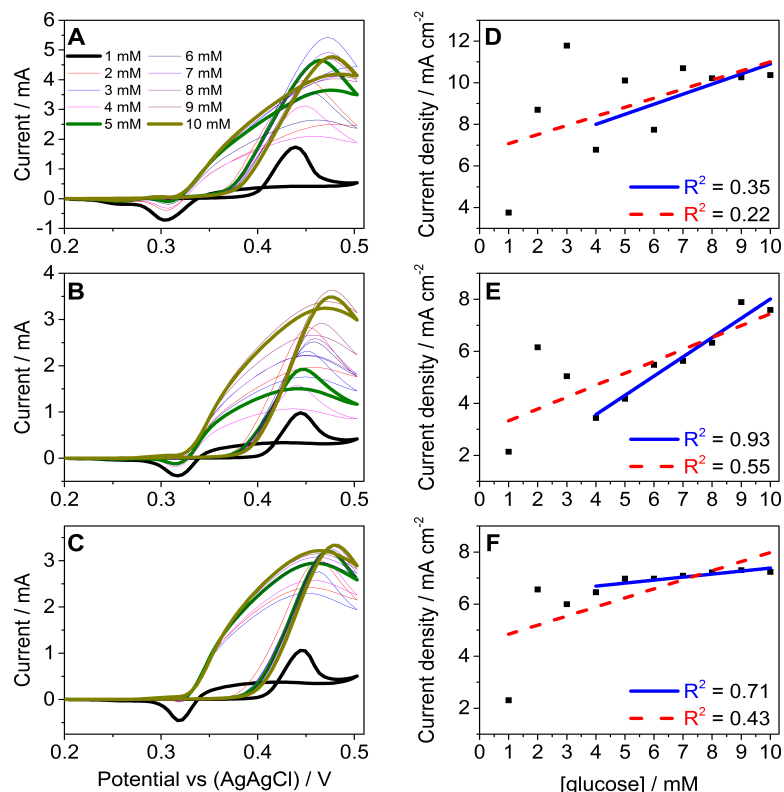

Figure $2 \mathrm{CV}$ response of $1-10 \mathrm{mM}$ glucose in $1 \mathrm{M} \mathrm{KOH}$ on A) $600 \mathrm{~s} \mathrm{~B}) 400 \mathrm{~s}$ and C) $100 \mathrm{~s}$ deposition of $1 \mathrm{mM} \mathrm{Ni}$ on BDDH. The thick curves on each graph is for 1,5 and $10 \mathrm{mM}$ of glucose. D-F shows the current response with respect to glucose concentration for 600,400 and 100 s respectively. The blue, solid line marks the linear correlation between the current density and the glucose concentration using only the latter data points $(n=7)$, while the red, dashed line is the linear correlation using all ten concentrations $(n=10)$.

[13] A. Tryk, K. Hashimoto, and A. Fujishima, Journal of the Electrochemical Society 146(3), 1081-1087 (1998).

[14] A. Tryk, K. Hashimoto, and A. Fujishima, Journal of the Electrochemical Society 145(6), 1870-1876 (1998).

[15] H. Kawarada, Surface Science Reports 26(7), 205-259 (1996).

[16] M. I. Landstrass and K. V. Ravi, Applied Physics Letters 55(1989), 975-977 (1989).

[17] C. E. Nebel, Science 318, 1391-1393 (2007).

[18] F. Maier, M. Riedel, B. Mantel, J. Ristein, and L. Ley, Physical Review Letters 85, 3472-3475 (2000).

[19] L. Ley, Surface Conductivity of Diamond, in: CVD Diamond for Electronic Devices and Sensors, edited by R. S. Sussmann, (John Wiley \& Sons, 2009), chap. 4, , 2009.

[20] C. M. Welch and R. G. Compton, Analytical and Bioanalytical Chemistry 384, 601619 (2006).

[21] J. Hu, X. Lu, J. S. Foord, and Q. Wang, Physica Status Solidi (A) Applications and Materials Science 206(9), 2057 2062 (2009).

[22] B. Liu, J. Hu, and J. S. Foord, Electrochemistry Communications 19(1), 46-49 (2012).

[23] C. Burda, X. Chen, R. Narayanan, and M. A. El-Sayed, Chemical Reviews 105, 1025-1102 (2005).

[24] K. E. Toghill and R. G. Compton, Electroanalysis 22(1718), 1947-1956 (2010).
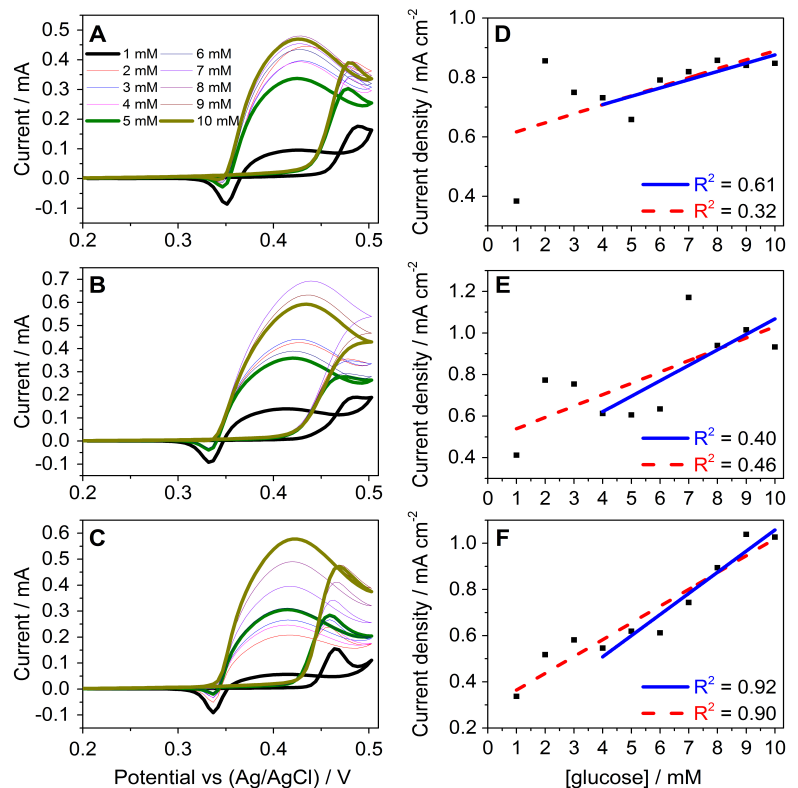

Figure $3 \mathrm{CV}$ response of $1-10 \mathrm{mM}$ glucose in $1 \mathrm{M} \mathrm{KOH}$ on $\mathrm{A}$ ) $600 \mathrm{~s} \mathrm{~B}) 400 \mathrm{~s}$ and C) $100 \mathrm{~s}$ deposition of $1 \mathrm{mM} \mathrm{Ni}$ on BDDO. The thick curves on each graph is for 1,5 and $10 \mathrm{mM}$ of glucose. D-F shows the current response with respect to glucose concentration for 600,400 and 100 s respectively.

[25] K.E. Toghill, L. Xiao, M.a. Phillips, and R. G. Compton, Sensors and Actuators, B: Chemical 147(2), 642-652 (2010).

[26] L. A. Hutton, M. Vidotti, A. N. Patel, M. E. Newton, P. R. Unwin, and J. V. MacPherson, Journal of Physical Chemistry C 115, 1649-1658 (2011).

[27] K. Toghill, L. Xiao, N. Stradiotto, and R. Compton, Electroanalysis 22(5), 491-500 (2010).

[28] M. Fleischmann, K. Korinek, and D. Pletcher, Journal of Electroanalytical Chemistry and Interfacial Electrochemistry 34, 499-503 (1972).

[29] N. R. Stradiotto, K.E. Toghill, L. Xiao，A. Moshar, and R. G. Compton, Electroanalysis 21(24), 2627-2633 (2009).

[30] J. Taraszewska and G. Roslonek, Journal of Electroanalytical Chemistry 364, 209-213 (1994).

[31] J. C. Harfield, K. E. Toghill, C. Batchelor-Mcauley, C. Downing, and R. G. Compton, Electroanalysis 23(4), 931-938 (2011).

[32] M. Fleischmann, K. Korinek, and D. Pletcher, Journal of Electroanalytical Chemistry and Interfacial Electrochemistry 31(1), 39-49 (1971).

[33] G. W. Muna, M. Partridge, H. Sirhan, B. VerVaet, N. Guerra, and H. Garner, Electroanalysis 26(10), 2145 2151 (2014).

[34] G. Yang, E. Liu, N. W. Khun, and S. P. Jiang, Journal of Electroanalytical Chemistry 627(1-2), 51-57 (2009).

[35] I. V. Shpilevaya, Surface Characterisation and Functional Properties of Modified Diamond Electrodes, PhD thesis, University of Oxford, 2014. 

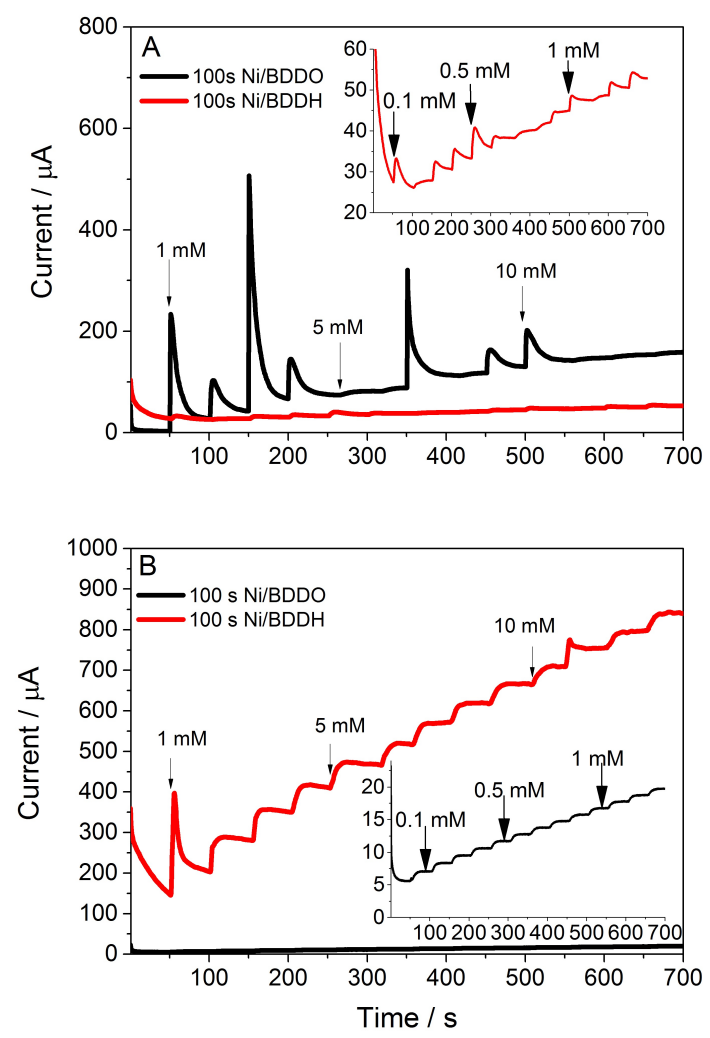

Figure 4 Amperometric measurements off $100 \mathrm{~s}$ deposition of $1 \mathrm{mM}$ Ni on BDDO (black) and BDDH (red) taken at $0.47 \mathrm{~V}$ in a stirred supporting electrolyte of $1 \mathrm{M} \mathrm{KOH}$ with $1 \mathrm{mM}$ and $0.1 \mathrm{mM}$ glucose injected every $50 \mathrm{~s}$. A) shows the variable behaviour of the glucose oxidising system and B) stable electrodes with reproducible behaviour.

[36] A. Salimi and M. Roushani, Electrochemistry Communications 7(9), 879-887 (2005).

[37] C. Zhao, C. Shao, M. Li, and K. Jiao, Talanta 71(4), 17691773 (2007).

[38] A. Safavi, N. Maleki, and E. Farjami, Biosensors and Bioelectronics 24(6), 1655-1660 (2009).

[39] W. Dai, M. Li, S. Gao, H. Li, C. Li, S. Xu, X. Wu, and B. Yang, Electrochimica Acta 187, 413-421 (2016).

[40] W. Visscher and E. Barendrecht, Electrochimica Acta 25(5), 651-655 (1980).

[41] R. Barnard, C. F. Randell, and F. L. Tye, Journal of Applied Electrochemistry 10(1), 109-125 (1980).

[42] X. Cheng, S. Zhang, H. Zhang, Q. Wang, P. He, and Y. Fang, Food Chemistry 106(2), 830-835 (2008).

[43] S. Kerzenmacher, J. Ducrée, R. Zengerle, and F. von Stetten, Journal of Power Sources 182(1), 1-17 (2008).

[44] C. Jin and I. Taniguchi, Materials Letters 61(11-12), 23652367 (2007).

[45] S. Prilutsky, P. Schechner, E. Bubis, V. Makarov, E. Zussman, and Y. Cohen, Electrochimica Acta 55(11), 36943702 (2010). 